\title{
Perencanaan Metode ABC sebagai Alternatif Penentuan Tarif Jasa Rawat Inap dalam Rangka Peningkatan Keunggulan Kompetitif
}

\author{
Astari Mei Neni \\ Accounting Department, Faculty of Economy \\ Maulana Malik Ibrahim, State Islamic University of Malang, \\ Indonesia
}

The research purpose is to find out the extent to which the application of activity based costing $(A B C)$ as an auxiliary apparatus management in order to the tariff is services inpatient ward to increase a competitive advantage in the hospital. This research using a method of quantitative descriptive then analyzed by activity based costing. Next comparing the fare long with the new rate based on fee-based costing activity. Then compare the new rate with the fare of another hospital in Blitar. There is a difference result of the calculation rate inpatient services using $A B C$ method and the traditional method. The $A B C$ method propose a hospital tariff in an effective and efficient rate, hence it will enhance the hospital competitive advantage to other similar institution

Keywords: activity based costing, tariff, hospital

\section{PENDAHULUAN}

Dalam menciptakan keunggulan bersaing, perusahaan harus menyediakan layanan dan produk yang berkualitas tinggi serta harga yang lebih murah dibandingkan pesaing (Baykasoglu \& Kaplanoglu: 2008), karena pelanggan lebih tertarik memilih barang dengan harga yang terjangkau tetapi dengan kualitas yang sama atau bahkan lebih baik dari pesaing. Bergman (1995), mengatakan harga adalah faktor yang menentukan kepuasan pelanggan. Dengan tuntutan seperti itu para manajer perusahaan memerlukan informasi mengenai biaya produksi yang digunakan dalam rangka memproduksi produk yang akan dilempar ke pasaran. Dengan mempelajari biaya produksi maka harapan manajer adalah menekan biaya agar dapat melakukan penghematan dan pengendalian biaya produksi dalam rangka untuk dapat menciptakan harga jual yang kompetitif (Siswanto, 2004).

Harga jual tidak boleh terlalu rendah agar dapat menutup semua biaya yang dikeluarkan perusahaan dan memberikan keuntungan yang diinginkan, juga tidak boleh terlalu tinggi agar 
perusahaan dapat bersaing dengan parapesaingnya. Suatu perusahaan dapat menetapkan harga jual dengan tepat jika perusahaan dapat menghitung biaya produksi dengan tepat juga. Oleh karena itu perhitungan biaya produksi yang dikeluarkan perusahaan untuk menghasilkan suatu produk pun haruslah akurat, sehingga perusahaan dapat menentukan harga jual yang kompetitif di pasar.

Menurut Saputra (2012), Produk dan jasa sebagai suatu hasil dari kegiatan ekonomi, merupakan serangkaian aktivitas yang melibatkan sumber daya yang ada. Penggunaan sumber daya dalam meninapkan aktivitas bisnis menimbulkan biaya. Biaya biaya tersebut memerlukan proses pembebanan kepada produk dan jasa yang dihasilkan. Dengan demikian, melalui proses pembebanan biaya secara akurat dan rasional, pelanggan sebagai konsumen merasa puas apabila memperoleh produk atau jasa sesuai dengan pengorbanan yang harus dilakukan untuk memperoleh produk dan jasa tersebut.

Salah satu solusi untuk memenangkan persaingan adalah dengan cara menentukan tarif yang lebih rendah dan kualitas atau jasa yang lebih tinggi daripada pesaing, dan hal tersebut dapat dilakukan dengan menghitung secara akurat biaya tetap dan biaya variabel yang dikeluarkan oleh perusahaan.

Selama ini pihak rumah sakit dalam menentukan harga pokoknya hanya menggunakan metode biaya tradisional yang penentuan harga pokoknya tidak lagi mencerminkan aktivitas yang spesifik karena banyaknya kategori biaya yang bersifat tidak langsung. Sehingga perlu diterapkannya metode penentuan harga pokok produk berdasarkan aktivitasnya (activity based) atau lebih dikenal dengan nama Activity Based Costing System (Mulyadi, 2003).

Dengan berkembangnya dunia teknologi, metode biaya tradisional mulai dirasakan tidak mampu menghasilkan biaya produk yang akurat lagi: Maka diperlukan metode yang dapat menghitung biaya produksi yang akurat, dewasa ini telah berkembang metode Activity Based Costing yang merupakan pendekatan penentuan biaya produk yang membebankan biaya produk atau jasa berdasarkan konsumsi sumber daya oleh aktivitas, dan aktivitas yang dibutuhkan tersebut menggunakan sumber daya yang menyebabkan timbulnya biaya. Sumber daya dibebankan ke aktivitas, kemudian aktivitas dibebankan ke objek 
biaya berdasarkan penggunaannya. $A B C$ memperkenalkan hubungan sebab akibat antara pemicu biaya (costdriver) dengan aktivitas.

Menurut (Mulyadi: 1993), Perbedaan utama perhitungan harga pokok produk antara akuntansi biaya tradisional dengan Activity Based Costing adalah jumlah pemicu biaya yang digunakan. Dalam penentuan harga pokok produk dengan metode Activity Based Costing menggunakan pemicu biaya dalam jumlah lebih banyak dibandingkan dalam metode akuntansi biaya tradisional yang hanya menggunakan satu atau dua pemicu biaya berdasarkan unit.

Berdasarkan penelitian Rendy dan Devie (2013), Terdapat pengaruh antara Activity Based Costing terhadap keunggulan bersaing dimana penerapan Activity Based Costing pada perusahaan yang baik akan mampu meningkatkan keunggulan bersaing yang dimiliki oleh perusahaan dan pengaruh antara keunggulan bersaing terhadap kinerja perusahaan dimana peningkatan keunggulan bersaing perusahaan akan mampu meningkatkan kinerja perusahaan pula, sehingga pengaruh antara Activity Based Costing terhadap kinerja perusahaan dimana penerapan Activity Based Costing yang baik akan mampu meningkatkan kinerja perusahaan, baik dari kinerja keuangan maupun operasionalnya.

Rumah Sakit Aminah Blitar merupakan Rumah Sakit Umum milik swasta yang melayani kesehatan bagi masyarakat sekitar. Ada beberapa unit yang diterapkan oleh rumah sakit ini, diantaranya: UGD 24 jam, Rawat Inap, VIP, Kelas I, II dan III, Poli Umum, Poli Gigi, Poli Bedah, Poli Anak, poli urologi, poli penyakit dalam, poli syaraf, Intensive Care Unit (ICU), konsultasi gizi. Dari beberapa unit yang ada dirumah sakit tersebut peneliti fokus pada Unit Rawat Inap. Dalam menentukan biaya rawat inap rumah sakit Aminah masih memakai metode biaya tradisional. Padahal perhitungan biaya rawat inap sangat penting, karena berkaitan dengan penentuan harga pokok jasa rawat inap, yang pada akhirnya akan mempengaruhi penentuan harga jual atau tarif rawat inap, metode yang digunakan oleh Rumah Sakit Aminah Blitar dianggap kurang mampu menyediakan informasi yang akurat. 
Perencanaan Metode $A B C$

\section{TINJAUAN PUST AKA}

Pengertian Activity Based Costing

Activity Based Costing (ABC) adalah: "Activity Based Costing adalah sistem informasi biaya yang menyediaan informasi lengkap tentang aktivitas untuk memungkinkan personel perusahaan melakukan pengelolaan terhadap aktivitas (Mulyadi, 2003: 25).

Sistem informasi ini menggunakan aktivitas sebagai basis serta pengurangan biaya dan penentuan secara akurat biaya produk atau jasa sebagai tujuan. Sistem informasi ini diterapkan dalam perusahaan manufaktur, jasa, dan dagang (Mulyadi, 2003: 40).

Activity Based Costing System mengendalikan biaya melalui penyediaan informasi tentang aktivitas yang menjadi penyebab timbulnya biaya. Dasar pemikiran yang melandasi sistem informasi biaya ini adalah "biaya ada penyebabnya, dan penyebab biaya dapat dikelola". Jika manajer berkeinginan untuk mengurangi biaya, ia harus melakukan pengelolaan terhadap penyebab timbulnya biaya, yaitu aktivitas.

\section{Activity Based Costing Dalam Perspektif Islam}

Islam menggambarkan suatu pasar bebas dimana harga yang sewajarnya ditentukan oleh kekuatan permintaan dan penawaran. Harga komoditas apapun ditentukan dengan mengingat biaya bahan baku dan produksi, selain itu tenaga kerja langsung.

Ibnu Khaldun dalam buku karyanya "Muqaddimah" mengemukakan sebuah teori "Model Dinamika" yang mempunyai pandangan jelas bagaimana faktor-faktor dinamika sosial, moral, ekonomi, dan politik saling berbeda namun saling berhubungan satu dengan lainnya bagi kemajuan maupun kemunduran sebuah lingkungan masyarakat atau pemerintahan sebuah wilayah (negara).

Dalam penentuan harga di pasar atas sebuah produksi, faktor yang sangat berpengaruh adalah permintaan dan penawaran. Ibnu Khaldun menekankan bahwa kenaikan penawaran atau penurunan permintaan menyebabkan kenaikan harga, demikian pula sebaliknya penurunan penawaran atau kenaikan permintaan akan menyebabkan penurunan harga.

Penurunan harga yang sangat drastis akan merugikan pengrajin dan pedagang serta mendorong mereka keluar dari 
pasar, sedangkan kenaikan harga yang drastis akan menyusahkan konsumen. Harga "damai" dalam kasus seperti ini sangat diharapkan oleh kedua belah pihak, karena ia tidak saja memungkinkan para pedagang mendapatkan tingkat pengembalian yang ditolerir oleh pasar dan juga mampu menciptakan kegairahan pasar dengan meningktakan penjualan untuk memperoleh tingkat keuntungan dan kemakmuran tertentu.

Dengan demikian, tingkat harga yang stabil dengan biaya hidup yang relatif rendah menjadi pilihan bagi masyarakat dengan sudut pandang pertumbuhan dan keadilan dalam perbandingan masa inflasi dan deflasi. Inflasi akan merusak keadilan, sedangkan deflasi mengurangi insentif dan efisiensi. Harga rendah untuk kebutuhan pokok seharusnya tidak dicapai melalui penetapan harga baku oleh negara karena hal itu akan merusak insentif bagi produksi.

\section{Pembebanan Biaya Overhead Pada Activity Based Costing}

Menurut Rudianto (2013: 165) terdapat dua tahapan pembebanan biaya overhead dengan metode Activity Based Costing yaitu:

1. Biaya overhead dibebankan pada aktivitas-aktivitas. Dalam tahapan ini di perlukan 5 (lima) langkah yang dilakukan yaitu:

a. Mengidentifikasi aktivitas.

b. Menentukan biaya yang terkait dengan masing-masing aktivitas.

c. Mengelompokkan aktivitas yang seragam menjadi satu. Pemisahan

d. Menggabungkan biaya dari aktivitas yang dikelompokkan.

e. Menghitung tarif per kelompok aktivitas (homogeny cost pool

2. Membebankan biaya aktivitas pada produk.

Setelah tarif per kelompok aktivitas diketahui maka dapat dilakukan perhitungan biaya overhead yang dibebankan pada produk adalah sebagai berikut:

Overhead yang dibebankan $=$ Tarif kelompok $\times$ Jumlah Konsumsi tiap Produk. 


\section{METODOLOGI PENELITIAN}

Penelitian ini menggunakan metode kuantitatif deskriptif, yaitu pendekatan yang pendekatan ilmiah terhadap pengambilan keputusan manajerial dan ekonomi. Metode kuantitatif yaitu metode yang menekankan pada pengujian teori kemudian dianalisis melalui suatu penghitungan dan didiskripsikan hasil dari perhitungan tersebut.

Untuk memperoleh data yang penulis butuhkan dalam penelitin ini, penulis melakukan penelitian pada Rumah Sakit Aminah Blitar Jl. Veteran No. 39 atau Jl. TGP No. 01 Kota Blitar.

\section{HASIL PENELITIAN}

Data yang digunakan dalam menetukan tarif jasa rawat inap dengan metode activity based costing antara lain data biaya rawat inap, data pendukung jumlah pasien rawat inap, data pendukung lama hari perawatan pasien rawat inap, data pendukung jumlah dan luas kamar rawat inap, data tarif konsumsi tiap kelas.

Dari hasil penelitian pada Rumah Sakit Aminah di dapat aktivitas-aktivitas yang ada didalam rawat inap. Dalam hubungannya dengan penetapan tarif kamar rawat inap, biaya perawatan pasien oleh perawat secara tidak langsung turut mempengaruhi aktifitas bagian rawat inap, maka aktivitas ini termasuk dalam kategori unit level activity cost. Dialokasikan secara profesional pada setiap tipe kamar.

Seluruh tipe kamar rawat inap rumah sakit memerlukan tenaga listrik untuk menjalankan peralatan elektronik, untuk penerangan kamar atau fasilitas yang ada di masing-masing kamar dan air untuk mandi. Untuk penggunaan listrik dan air termasuk kategori unit level activity cost, karena biaya berubah sesuai dengan perubahan KWH kamar yang terpakai. Fasilitas yang mengkonsumsi listrik meliputi: TV, Kulkas, alat pemanas, lampu, AC.

Pasien yang menjalani rawat inap membutuhkan makanan dan minuman untuk mempercepat penyembuhan pasien, yang termasuk dalam kategori Unit level activity costs, karena tidak tergantung pada lamanya pasien menjalani rawat inap.

Biaya kebersihan adalah biaya dikeluarkan untuk menunjang kebersihan lingkungan rawat inap, sehingga pasien merasa nyaman. Biaya ini termasuk dalam kategori Batch related activity costs. Pelayanan administasi diberikan untuk menunjang 
kelancaran dalam penyediaan aktivitas sarana dan prasarana. Termasuk kategori batch related activity based costing.

Biaya bahan habis pakai adalah biaya yang digunakan oleh perawat untuk pasien, juga paket yang diberikan kepada pasien rawat inap pada hari pertama dirawat di rumah sakit. Termasuk kategori batch related activity based costing. Biaya penyusutan bangunan merupakan fasilitiy sustaining activity cost karena seluruh tipe kamar menggunakan bangunan dan pembebanan masing-masing kamar.

Pembebanan penyusutan fasilitas ini berdasarkan masingmasing tipe kamar. Penyusutan fasilitas ini termasuk dalam kategori facility sustaining activity cost karena seluruh tipe kamar menggunakan fasilitas yang ada dalam masing - masing tipe kamar dan pembenannya berdasarkan jumlah hari pakai.

Kelas

Kelas VIP

Kelas I

Kelas II

Kelas III
RS aminah

blitar

375.000,-

250.000,-

150.000,-

60.000,-
RS Aminah

Blitar (ABC)

173.309,-

145.152,-

133.070,-

124.002,-
RS Syuhada

Haji Blitar

300.000,-

200.000,-

75.000,-

45.000,-

Sumber: Pengolahan Data RS

Tabel diatas merupakan perbandingan tarif yang dihitung dengan menggunakan tarif tradsional dan Activity Based Costing, dapat dilihat terdapat selisih lebih besar antara tarif RS Aminah yang dihitung menggunakan metode tradisional dengan tarif RS Syuhada' Haji. Sedangkan tarif RS Aminah yang dihitung menggunakan metode Activity Based Costing jauh lebih kecil dibandingkan dengan tarif RS Syuhada' Haji.

Dapat disimpulkan menghitung tarif jasa rawat inap dengan menggunakan metode Activity Based Costing jauh lebih efektif dan efesien dimana manajer rumah sakit dapat membuat harga dibawah pesaing selain itu juga dapat menutupi seluruh biaya yang dikeluarkan, dimana biaya overhead dibebankan pada masing - masing konsumsi aktivitas seperti aktivitas perawatan pasien, pemeliharaan inventaris, pemeliharaan pasien, pelayanan pasien, dan dibebankan pada banyak cost driver seperti jumlah pasien yang berkunjung, luas lantai, KWH listrik yang digunakan, jumlah hari pasien dirawat.

Dengan menggunakan metode Activity Based Costing tarif yang dihasilkan lebih kecil dengan rumah sakit yang lain di Blitar sehingga dengan harga yang dapat bersaing dengan rumah sakit 
syuhada haji dan memiliki fasilitas yang cukup lengkap dan memadai maka RS Aminah dapat bersaing dengan RS yang lain di Blitar kususnya rumah sakit syuhada haji. RS harus menetapkan pembiayaan pelayanan kesehatan yang baik dengan tetap memperhitungkan resiko dan hasil yang diperoleh dalam menetapkan besarnya tarif yang harus dibayarkan oleh pemakai jasa.

\section{KESIMPULAN}

Berdasarkan hasil penelitian dapat menarik kesimpulan tentang penerapan metode Activity Based Costing sebagai alat bantu manajemen dalam rangka penerapan tarif jasa rawat inap di Rumah Sakit Aminah Blitar. Penghitungan tarif jasa rawat inap pada Rumah Sakit Aminah Blitar masih menggunakan metode Tradisional. Dimana metode ini banyak menimbulkan distorsi biaya, hal ini dikarenakan biaya overhead pada masing - masing produk hanya dibebankan pada satu cost driver saja. Sedangkan pada metode Activity Based Costing, biaya overhead dibebankan pada lebih dari satu cost driver, sehingga dalam metode Activity Based Costing telah mampu mengalokasikan biaya aktivitas kesetiap kamar secara tepat berdasarkan konsumsi masing masing aktivitas.

Perhitungan tarif jasa rawat inap dengan menggunakan metode Activity Based Costing dilakukan melalui beberapa tahap, yaitu tahap pertama biaya ditelusuri ke aktivitas yang menimbulkan biaya dan tahap ke dua membebankan biaya aktivitas ke produk. Sedangkan tarif diperoleh dengan menabahkan cost rawat inap dengan laba yang di harapkan. Hasil perhitungan tarif dengan menggunakan metode Activity Based Costing pada Rumah Sakit Aminah adalah pada kelas VIP Rp 173.309, Kelas I Rp 145.152, Kelas II Rp 133.070, Kelas III Rp 124.002. Tarif yang digunakan pada saat ini adalah Kelas VIP Rp 375.000 , Kelas I Rp 250.000, Kelas II Rp 150.000, Kelas III Rp 60.000. Terdapat selisih tarif yang lebih rendah pada kelas VIP Rp 201.691, Kelas I Rp 104.848, Kelas II Rp 16.930 dan selisih tarif lebih tinggi pada Kelas III sebesar Rp 64.002,--

Dengan menerapkan metode Activity Based Costing tarif yang dihasilkan jauh lebih rendah dari tarif yang dihitung dengan menggunakan metode tradisional, sehingga dengan menggunakan metode Activity Based Costing rumah sakit dapat bersaing dengan rumah sakit yang lain di Blitar khususnya 


\section{SARAN}

Saran yang bisa penulis berikan dari hasil penelitian yang dilakukan, hendaknya Rumah Sakit perlu mempertimbangkan penerapan metode Activity Based Costing sebagai alternatif dalam menetapkan tarif jasa rawat inap. Karena dengan metode $A B C$ Rumah Sakit dapat mempertahankan usaha dan dapat bersaing dengan Rumah Sakit yang lain.

Rumah Sakit Aminah Blitar sebaiknya dalam menetukan tarif jasa rawat inap tidak hanya melakukan perkiraan saja yaitu dengan membandingkan tarif jasa rawat inap rumah sakit lain, akan tetapi perlu adanya perhitungan yang lebih efektif dan efesien dalam pengalokasian biaya yang dikeluarkan.

\section{DAFTAR PUSTAKA}

Adiwarman. Azwar Karim. (2008). Sejarah Pemikiran Ekonomi Islam. Jakarta. PT Raja Grapindo Persada.

Anggraini. Ninik. Penerapan metode Activity Based Costing System dalam menentukan besarnya tarif jasa rawat inap (studi kasus pada RSB Nirmala,Kediri). Cendekia Akuntansi vol.1 No.1 - Januari 2013.

Ayub, Muhammad. (2002). Understanding Islamic Finance. Jakarta. Gramedia.

Baykasoglu, A. \& Kaplanoglu, V.(2008). Application of Activity Based Costing to a land transportation company: A case study. Int. J. Production Economics 116, 308-324.

Bergman, R.L.(1995). Integrating marketing, operations, and purchasing to create value. Omega 23(2), 159-172.

Garrison, Ray H and Noreen, Eric W. (2000). Akuntansi Manajerial, Buku 1, Cetakan kedelapan. Jakarta. Salemba Empat.

Hansen, Don R and Maryanne, M Mowen. (2004). Manajemen Biaya, Edisi 7. Jakarta. Salemba Empat.

Hansen, Don R and Maryanne, M Mowen. (2012). Manajemen Biaya. Jakarta. Salemba Empat. 
Perencanaan Metode $A B C$

Hansen, Don R., Mowen, Maryanne M. (2006). Management Accounting; Akuntansi Manajemen, buku 1, edisi ketujuh, Salemba Empat.

Mardiasmo. (1994). Akuntansi Biaya, Edisi Pertama, Cetakan Pertama. Yogyakarta.

Marismiati, Peranan Metode Activity-Based Costing System Dalam Menentukan Harga. Jurnal Ekonomi Dan Informasi Akuntansi (JENIUS). Vol. 1 No. 1 Januari 2011

Muhammad Ahma, dan Ahmad Fathi. (1999). Sistem, Prinsip, dan Tujuan Ekonomi Islam. Bandung. CV Pustaka Sakti.

Mulyadi. (1993). Akuntansi Manajemen, Konsep, Manfaat dan Rekayasa. Edisi 2. Yogyakarta. BP STIE YKPN. . (2003). Activity Based Cost System Sistem Informasi Biaya untuk Pengurangan Biaya. Yogyakarta: UPPAMP YKPN.

- (2005). Akuntansi Biaya. Edisi 5, cetakan ketujuh. Yogyakarta.UPP AMP YKPN.

(2007). Sistem Perencanaan dan Pengendalian Manajemen (Sistem Pelipatganda Kinerja Perusahaan). Jakarta. Salemba Empat.

Porter. Michael. (2008). Competitiv Advantage (Keunggulan Bersaing). Jakarta. Karisma Publishing Group.

Saputra. Dani. (2012). Penerapan Metode Activity Based Costing Dalam Menetukan Besarnya Tarif Jasa Rawat Inap Pada RS Hikmah. Skripsi. Makassar. Fakultas Ekonomi Universitas Hasánuddin Makassar.

Siswanto. (2004). Activity Based Costing Sebagai Metode Alternatif Meraih Keunggulan Kompetitif. Jurnal Pendidikan Akuntansi Indonesia. 3(1). 71- 77.

Supriyono. (1994). Akuntansi Biaya:Pengumpulan Biaya dan Penentuan Harga Pokok Produksi, Edisi 2. Yogyakarta. BPFE. 
Supriyono. (1999). Akuntansi Biaya:pengumpulan biaya dan penetuan harga pokok, Edisi 2, Cetakan keduabelas. Yogyakarta. BPFE.

Supriyono. (2002). Akuntansi Manajemen, Proses Pengendalian Manajemen. STIE YKPN, Yogyakarta.

Tunggal, Amin Wijaya. (2000) . Activity Based Costing untuk Manufakturing dan Pemasaran. Jakarta : Rineke Cipta.

Warindrani, Armila Krisna. (2006). Akuntansi Manajemen. Edisi Pertama, Cetakan Pertama. Yogyakarta. Graha Ilmu. populasi 